\title{
Micro- and Nanofibrillated Cellulose (MNFC) from Pineapple (Ananas comosus) Stems and Their Application on Polyvinyl Acetate (PVAc) and Urea-Formaldehyde (UF) Wood Adhesives
}

\author{
Priscilla Rigg-Aguilar, ${ }^{1}$ Roger Moya $\left(\mathbb{D},{ }^{1}\right.$ Gloria S. Oporto-Velásquez $\mathbb{D}^{2}$ \\ José Vega-Baudrit $\left(10,{ }^{3}\right.$ Ricardo Starbird, ${ }^{4}$ Allen Puente-Urbina, ${ }^{4}$ Daniel Méndez, ${ }^{5}$ \\ Luis Diego Potosme, ${ }^{5}$ and Marianelly Esquivel ${ }^{5}$ \\ ${ }^{1}$ Escuela de Ingeniería Forestal, Instituto Tecnológico de Costa Rica, Apartado Cartago, Costa Rica 159-7050 \\ ${ }^{2}$ School of Forestry and Natural Resources, Wood Science and Technology, West Virginia University, Morgantown, WV 26506, USA \\ ${ }^{3}$ Laboratorio Nacional Nanotecnologia (LANOTEC), Centro Nacional de Alta Tecnologia-CENAT, San Jose, Costa Rica \\ ${ }^{4}$ Centro de Investigación y de Servicios Químicos y Microbiológicos (CEQIATEC), Escuela de Química, Instituto Tecnológico de \\ Costa Rica, Cartago, Costa Rica \\ ${ }^{5}$ Laboratorio de Polímeros, Escuela de Química, Universidad Nacional de Costa Rica, Heredia., Costa Rica
}

Correspondence should be addressed to Roger Moya; rmoya@itcr.ac.cr

Received 13 December 2019; Revised 12 June 2020; Accepted 6 July 2020; Published 1 August 2020

Academic Editor: Zafar Iqbal

Copyright (C) 2020 Priscilla Rigg-Aguilar et al. This is an open access article distributed under the Creative Commons Attribution License, which permits unrestricted use, distribution, and reproduction in any medium, provided the original work is properly cited.

\begin{abstract}
Micro- and nanofibrillated cellulose (MNFC) was extracted from pineapple stems by acid hydrolysis, then characterized and tested in two concentrations (0.5 and $1.0 \mathrm{wt} \%$ ) in polyvinyl acetate (PVAc) and urea-formaldehyde (UF) adhesives. The modified adhesives were used to glue three tropical wood species (Vochysia ferruginea, Cordia alliodora, and Gmelina arborea), and their corresponding bond strength resistance was determined. MNFC and the correspondent adhesives were characterized by TGA, FTIR, SEM, TEM, AFM, and viscosity determination. The TGA analysis of MNFC showed three decomposition reactions. The SEM, TEM, and AFM evaluations demonstrated the presence of micro- and nanosized dimensions of particles after the acid hydrolysis of pineapple stems. Adding $1 \mathrm{wt} \%$ MNFC to PVAc and UF adhesives increased their thermal stability in similar manner. Viscosity diminished in both modified adhesives with MNFC; however, this reduction did not affect the adhesion properties in the tropical wood tested. MNFC added to PVAc and UF adhesives improved shear strength (SS) of the glue line in the three tropical species tested. The highest SS increase was obtained when adding $0.5 \mathrm{wt} \% \mathrm{MNFC}$ to PVAc in V. ferruginea, and $1 \mathrm{wt} \%$ MNFC concentration in the case of C. alliodora and G. arborea. In the case of UF adhesives, the application of $1 \mathrm{wt} \%$ MNFC produced significant differences in SS for the three tropical species studied.
\end{abstract}

\section{Introduction}

In recent years, and considering their abundance, annual crops have been used as raw materials to extract micro- and nanofibrillated cellulose $[1,2]$. Several authors have studied their extraction from corn, wheat, rice, coconut, soy [3], jute, and pineapple leaves $[1,2]$.

The annual crop pineapple (Ananas comosus), with a world production of around 24.8 million tons per year [2, 4], produces large amounts of residues in the form of leaves, stems, crowns, and fruit peel that are not used [5]. In Costa Rica for instance, this crop was introduced in 1970, and by 2014, there were approximately 37660 ha of pineapple-sown fields available [6]. From these fields, nearly 300 tons of stubble are produced [6] which can be an important source of high-value materials [7]. One possible utilization for the pineapple wastes has been the extraction of natural fibers for rope and textile manufacturing [7] or pulp production [8]. 
Considering pineapple residues' availability, the aim of this work was to produce and characterize nanocellulose from pineapple stems and determine the effect of adding this material on two commercial woody adhesives: urea-formaldehyde (UF) and polyvinyl acetate (PVAc). While the behavior of adhesives with nanocellulosic material from crops has been explored with certain success in temperate countries, there is no information regarding their performance in tropical countries $[9,10]$ or in general tropical wood adhesion [11]. The adhesives were applied to the following tropical species: Vochysia ferruginea, Cordia alliodora, and Gmelina arborea (main wood produced in Costa Rica from fast-growth plantation), and their shear strength was evaluated. The rationale to perform this work was based on preliminary research which demonstrated that adding nanocellulose to traditional wood adhesives (UF and PVAc) improves the bondability between woody elements [12-15].

Mahrdt el al. [12] demonstrated that even though the incorporation of microfibrillated cellulose (MFC) increased the viscosity of the adhesive and delayed the adhesive's cure, the interaction of UF with MFC leads to a shift in the size distribution of adhesive particles towards larger particles for the UF-MFC compared to UF alone. Considering this fact, a higher fraction of adhesive is available for bond-line formation, and a larger part of the wood particles is covered with adhesive. Therefore, it was proposed that the change in the adhesive distribution together with improved adhesive toughness were the main contributions to the improved board strength. Ayrilmis et al. [13] combined microfibrillated cellulose (MFC) with urea-formaldehyde adhesive and evaluated the adhesive performance on laminated veneer lumber (LVL). In general, the authors' main findings indicated that the cellulosic filler improved the bonding performance which was quantified through the tensile shear strength determination of the LVL products.

\section{Materials and Methods}

2.1. Materials. Pineapple (Ananas comosus) stems were provided by Reuti-piña, which planted pineapple crops in the northern part of Costa Rica. The plantations had a density of 70,000 plants per hectare, and their age was 18 months old.

Two water-based adhesives were tested in combination with the micro- and nanofibrillated cellulose (MNFC) produced in this research from pineapple stems. Adhesive 1: polyvinyl acetate (PVAc) (Resistol M.R. 850, produced by Henkel Capital S.A.-54.5-55.0\% solid content and 1600-2000 cPs viscosity). Adhesive 2: urea-formaldehyde (UF) (Resina CR560 U-F, manufactured by Química Centroamericana Quibor S.A.-48\% solid content and $650-900 \mathrm{cPs}$ viscosity). The technical description of the adhesive 2 indicated that it is prepared with 4 components: resin (51\%), water (26\%), wheat flour as binder (20\%), and ammonium sulfate as catalyst (3\%).

Three tropical species were used to evaluate the modified adhesives. These were botarrama (Vochysia ferruginea), laurel (Cordia alliodora) and gmelina (Gmelina arborea). They were selected because of their commercial importance in the manufacture of pallets in Costa Rica [16]. The specific gravity or basic density of these species are 0.44 for $V$. ferruginea, 0.40 for C. alliodora, and 0.41 for G. arborea [16].

2.2. Micro- and Nanofibrillated Cellulose (MNFC) Production. Figure 1 presents the process used in this research to extract MNFC from pineapple stems. The general process was performed as described by Oun and Rhim [17], but with slight modifications related to acid concentrations and reaction times.

2.2.1. Fibers from Pineapple Stems. Pineapple stems were cut into $2 \mathrm{~cm}$ long pieces and then dried at $80^{\circ} \mathrm{C}$ until reaching $4 \%$ moisture content. Then, they were ground to $300 \mu \mathrm{m}$ size. A $2.5 \%$ sodium hydroxide $(\mathrm{NaOH})$ solution was prepared and poured into the ground pineapple stem. The mixture was then heated up to $100^{\circ} \mathrm{C}$ for $4 \mathrm{~h}$. Afterwards, the material was washed with distilled water until it reached neutral $\mathrm{pH}$ and then with bleached with $4 \%$ sodium hypochlorite $(\mathrm{NaClO})$ for $2 \mathrm{~h}$. Next, the material was washed with distilled water again to obtain neutral $\mathrm{pH}$.

2.2.2. MNFC from Pineapple Fibers. Fibers from Section 2.2.1 were firstly treated with an acid hydrolysis process using $37 \%$ hydrochloric acid ( $\mathrm{HCl}$ (aq.)) under reflux at $90^{\circ} \mathrm{C}$ for $30 \mathrm{~min}$. The hydrolyzed microcrystalline cellulose followed subsequent filtration and neutralization with distilled water until it reached neutral $\mathrm{pH}$ [18]. It is important to clarify that after this first hydrolysis, a simple vacuum filtration was performed. There was an intrinsic loss of material, but at this point, it is assumed that mostly microfibers, not much nanofibers, were available.

A second acid hydrolysis step was performed using $64 \%$ sulfuric acid $\left(\mathrm{H}_{2} \mathrm{SO}_{4}\right)$ at ambient temperature $\left(\right.$ ca. $\left.22^{\circ} \mathrm{C}\right)$ for $1 \mathrm{~h}$. MNFC final suspensions were washed with ultrapure water, and successive dilution and centrifugation process at $1200 \mathrm{rpm}$ were applied until the suspensions reached a $\mathrm{pH}$ between 3 and 5. After that, the suspensions were purified by a dialysis process. A final mechanical treatment using ultrasound for $10 \mathrm{~min}$ at an amplitude of $7 \mathrm{~Hz}$ was performed to get MNFC hydrogel $\left(0.033 \mathrm{~g} \mathrm{ml}^{-1}\right)$.

2.3. Preparation of Adhesives with MNFC. MNFC suspensions were added to polyvinyl acetate (PVAc) and urea formaldehyde (UF) in two concentrations: $0.5 \mathrm{wt} \%$ and $1.0 \mathrm{wt} \%$. The addition was performed based on the solid content of each adhesive, i.e., ca. 55\% for PVAc and $48 \%$ for UF. The denomination of the adhesives used for further test and analysis is presented in Table 1.

The preparation of the adhesives listed in Table 1 was performed as follows: $150 \mathrm{~g}$ of PVAc was stirred with a $45^{\circ}$ inclined blade agitator at $1600 \mathrm{rpm}$. Then, a proportion of MNFC gel (approximately $13.75 \mathrm{ml}$ of gel or $0.75 \mathrm{~g}$ of MNFC for $0.5 \%$ concentration and $27.5 \mathrm{ml}$ of gel or $1.5 \mathrm{~g}$ of MNFC for $1.0 \%$ concentration) was slowly added into the adhesive and under continuous stirring for 10 minutes. As for UF, the same general procedure was applied, but low amount of MNFC was added considering the lower solid content of this adhesive. For $0.5 \%$ MNFC concentration, $12 \mathrm{ml}$ of MNFC gel was added onto $76.5 \mathrm{~g}$ of the UF adhesive (ca. $0.3925 \mathrm{~g}$ of MNFC). For the $1 \% \mathrm{MNFC}$ 


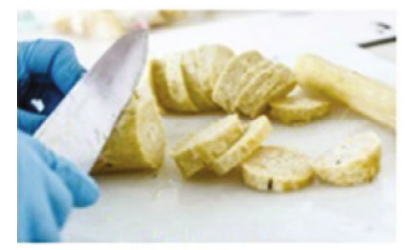

Biomass

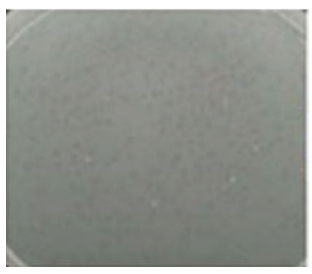

MNFC

hydrogel
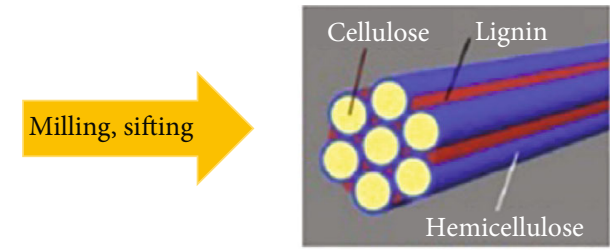

Cellulose fibers

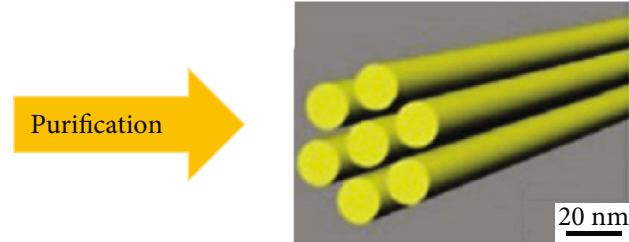

Purified cellulose
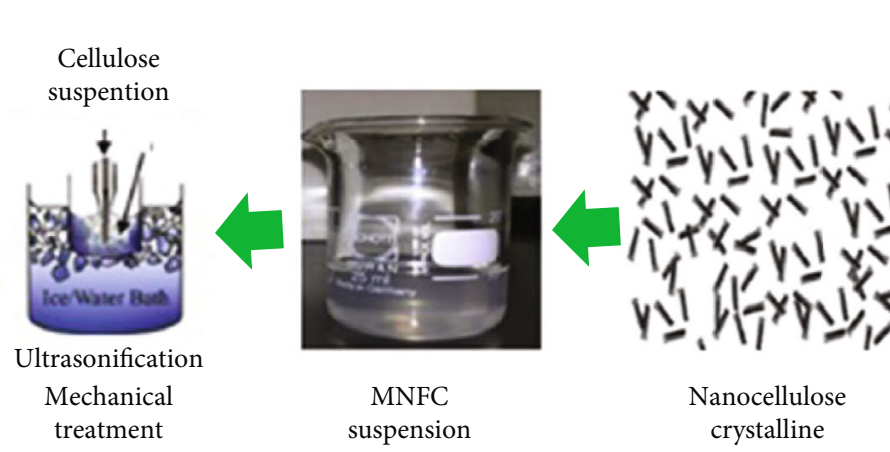

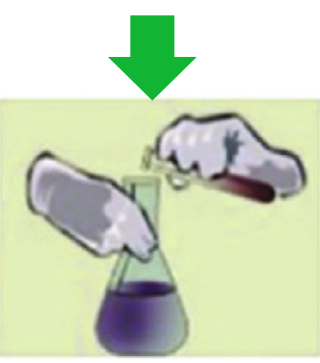

Chemical treatment

Figure 1: General process for the nanocellulose hydrogel production from pineapple stem (adaptation of [61, 62]).

TABLE 1: Characteristics of the adhesives used in this research.

\begin{tabular}{lcr}
\hline Adhesive type & MNFC concentration (wt\%) & Denomination \\
\hline & 0.0 & MNFC 0-PVAc \\
Polyvinyl acetate- (PVAc-) MNFC & 0.5 & MNFC 0.5-PVAc \\
& 1.0 & MNFC 1-PVAc \\
\hline Urea-formaldehyde- (UF-) MNFC & 0.0 & MNFC 0-UF \\
& 0.5 & MNFC 0.5-UF \\
\hline
\end{tabular}

concentration, $24 \mathrm{ml}$ of MNFC gel was added onto $76.5 \mathrm{~g}$ of the UF adhesive (ca. $0.765 \mathrm{~g}$ of MNFC).

\subsection{Characterization of MNFC and the Modified Adhesives.} MNFC was characterized using Atomic Force Microscopy (AFM), Scanning Electron Microscopy (SEM), and Transmission Electron Microscopy (TEM), for distribution and morphology. Also, MNFC was analyzed using Thermogravimetric Analysis (TGA) and Fourier-Transform Infrared Spectroscopy (FTIR). The pristine adhesives and their mixtures with MNFC were characterized using Thermogravimetric Analysis (TGA), FTIR, and bond strength resistance.

2.4.1. Thermogravimetric Analysis (TGA). Thermal stability of MNFC material and the modified adhesives were analyzed in triplicate using a TGA 5000 (TA Instruments). Thick films from the samples under study were prepared, following the next steps. A sample of approximately $5 \mathrm{~g}$ of the adhesives with MNFC was poured on a glass plate, and it was allowed to dry at room temperature $\left(\mathrm{ca} .22^{\circ} \mathrm{C}\right)$ for two days. Then, the film formed was detached from the glass and cut to a $1 \mathrm{~cm}$ diameter circular shape. Small subsamples of 6-7 mg from the films were analyzed in the TGA under nitrogen atmosphere $\left(90 \mathrm{ml} \mathrm{min}^{-1}\right.$ flow rate and $25^{\circ} \mathrm{C} \mathrm{min}^{-1}$ heating rate). The experiments run from ambient temperature up to $1000^{\circ} \mathrm{C}$. The analysis of data, which includes determination of initial degradation temperature (Ti), maximum degradation temperature (Tmax), final degradation temperature (Tf), percentage of remaining mass at initial temperature (MRi), remaining mass at maximum temperature (MRmax), and remaining mass at final temperature (MRf), was performed using the TA Instruments Universal Analysis Q500 software. Afterwards, the thermal stability, which measured the stability of resin with temperature, activation energy $(E)$, and entropy factor $(A)$ were determined. The final data were modelled (Equations (1)-(4)) with the Gaussian curve (Equation (1)) and MagicPlot software to determine its variables (Equation (2)). With a normal distribution and the constant " $c$ " equal to the standard deviation, the values of the initial and final temperatures correspond to $x_{0} \pm 3 c$, considering $99.7 \%$ of the population.

$$
\begin{aligned}
& f(x)=A E^{\frac{-(x-b)^{2}}{2 c^{2}},} \\
& f(x)=A E^{\frac{-\ln (2)\left(x-x_{0}\right)^{2}}{d x^{2}}}, \\
& -\frac{1}{2 c^{2}}=-\frac{\ln (2)}{d x^{2}},
\end{aligned}
$$




$$
c=\frac{d x}{\sqrt{2 \ln (2)}}
$$

Where $A, b$, and $c$ are real constants $(c>0), f(x)$ is the derivative of mass with respect to temperature, and $x$ the temperature.

Kinetics in each reaction was calculated by means of the Doyle model (Equation (5)) [19]. The model was applied to determine the following parameters for each reaction in both adhesives: $E$, which is the energy needed for each reaction to occur, and $A$, which is specific for each reaction [20].

$$
\ln [-\ln (1-\alpha)]=\ln \left(\frac{A E}{B R}\right)-1.0518 \frac{E}{R T}-5.33
$$

Where $\alpha$ is the degraded mass, $A$ the entropy factor, $E$ the activation energy, and $T$ the temperature.

2.4.2. Fourier-Transform Infrared (FTIR) Spectra. Functional groups present in the MNFC samples and modified adhesives were determined using FTIR analysis. Before the analysis, a $50 \mathrm{ml}$ of MNFC gel sample was placed in an oven during $24 \mathrm{~h}$ at $60^{\circ} \mathrm{C}$. In parallel, $2 \mathrm{~g}$ of the modified adhesives was placed in an oven at $103^{\circ} \mathrm{C}$ for $72 \mathrm{~h}$, and then the material was pulverized with a mortar. The FTIR spectra of the samples were acquired using a Thermo Scientific Nicolet 6700 equipped with an Attenuated Total Reflectance accessory within the range of $3800-800 \mathrm{~cm}^{-1}$, a resolution of $4 \mathrm{~cm}^{-1}$, and 16 scans. All spectra were analyzed using the software OMNIC.

\subsubsection{Morphology Analysis Using TEM, AFM, and SEM. For} TEM observations, dry samples of MNFC were diluted at 1.9 vol\% in distilled water. The samples were disintegrated using an ultrasonic bath for $15 \mathrm{~min}$ at a frequency of $40 \mathrm{kHz}$. After that, a 5-drop sample was placed on a TEM grid (covered with formvar), and it rested for 5 minutes for the grid to retain the sample. Then, the grid was left to dry for 2 days, and the samples were observed in a TEM (Jeol JEM 2100) at an acceleration voltage of $200 \mathrm{kV}$. A drop of the mixture of each modified adhesive was placed on paraffin film on top of two slides to obtain a fine sheet of the material to observe MNFC dispersion in the adhesives through the TEM.

For AFM observations, $1 \mathrm{ml}$ of the $1.9 \mathrm{vol} \%$ MNFC suspension was placed on a mica surface, and it was left there to air-dry for 2 days. The surface topography of the MNFC samples was observed by using an atomic force microscope (Asylum Research) operated in the air-tap mode. Silicon probes were used (model Tap150Al-G, rear part of the overhang covered with $\mathrm{Al}$ ) with resonance frequency of $150 \mathrm{kHz}$ and $5 \mathrm{~N} \mathrm{~m}^{-1}$ force constant.

For SEM observations, one drop of the $1.9 \mathrm{vol} \%$ solution was placed on a glass slide with carbon tape, and it was left there to air-dry for 3 days. Then, the dry sample was coated with gold-palladium before analysis. A SEM Jeol JSM-5900 LV at $20 \mathrm{kV}$ acceleration voltage was used. To measure MNFC using TEM and SEM micrographs, the software of the corresponding system (Gatan DigitalMicrograph) was used.
2.4.4. Viscosity of the Adhesives. The viscosity of the modified adhesives was measured at $20^{\circ} \mathrm{C}$ using a Discovery HR-3 hybrid rheometer with a parallel disc geometry of $25 \mathrm{~mm}$ diameter, $500 \mu \mathrm{m}$ between discs, applying shear rates between 0 and $200 \mathrm{~s}^{-1}$. Four repetitions for each sample were performed.

2.4.5. Bond Strength Resistance. The bond strength of the modified adhesives was tested using the glue line test (SS) according to ASTM D905-98 [21], after their application on wood samples of three tropical species (Vochysia ferruginea, Cordia alliodora, and Gmelina arborea). Ninety shear tests were carried out in total (30 samples per concentration $\mathrm{x} 3$ concentrations) per each species. Wood samples were dried at $12 \%$ moisture content for one week. The adhesive was applied according to manufacturer's specifications, which recommended $100 \mathrm{~g}$ adhesive per square meter wood surface. After applying the adhesive, the samples were pressed in a hydraulic press at $0.20 \mathrm{~N} \mathrm{~mm}^{-2}$ for 24 hours. After that, the samples were conditioned to $20^{\circ} \mathrm{C}$ and $60 \%$ relative humidity for two weeks prior the bond strength test. A Tinius Olsen hydraulic test machine with $50 \mathrm{kN}$ capacity was used for testing the adhesives performance on tropical woods.

2.5. Data Analysis. Compliance of the variables determined with the assumptions of the normal distribution, variance homogeneity and the presence of outliers, was verified. Subsequently, a variance analysis was performed to verify the effect of the MNFC adhesion (three levels: $0.0 \%, 0.5 \%$, and $1.0 \%)$ on the values of $E, A$, the different temperatures, and remaining masses in the various reactions of the decomposition kinetics, in addition to the bond strength resistance. The Tukey test at $99 \%$ confidence level was applied to determine the statistical difference among averages. The InfoStat software (InfoStat Company, version 2017, Buenos Aires, Argentina) was used for statistical analysis.

\section{Results and Discussion}

3.1. Thermal Stability Analysis. TGA analyses for pristine MNFC and for the modified adhesives with three concentrations of MNFC (0.0, $0.5 \%$, and $1.0 \%)$ are shown in Figures 2(a) and 2(b). As expected, MNFC loses water in the range temperature of $25-100^{\circ} \mathrm{C}$ (ca. $30 \%$ ) because it was prepared in aqueous environment. Two inflexions appear in $\mathrm{MNFC}$, at $200^{\circ} \mathrm{C}$ and at $350^{\circ} \mathrm{C}$ (Figures 2(a) and 2(b)) which corresponds to degradation temperatures. These results agreed with values presented by Kargarzadeh et al. [22], where temperatures of $230^{\circ} \mathrm{C}$ and $350^{\circ} \mathrm{C}$ are reported, and of Kumar et al. [23], who reported values of $220^{\circ} \mathrm{C}$ and $330^{\circ} \mathrm{C}$ for MNFC extracted by acid hydrolysis from sugarcane and kenaf, respectively.

With the TGA data and using Equation (5), it was possible to obtain 3 fitting curves that correspond to 3 reactions (Figure 3). Reaction 1 occurred between $169^{\circ} \mathrm{C}$ and $252^{\circ} \mathrm{C}$, reaction 2 occurred between $199^{\circ} \mathrm{C}$ and $282^{\circ} \mathrm{C}$, and reaction 3 occurred along the whole decomposition process, from $37^{\circ} \mathrm{C}$ to $693^{\circ} \mathrm{C}$. Initial degradation temperature (Ti) of MNFC samples was lower than the ones reported by other studies; 

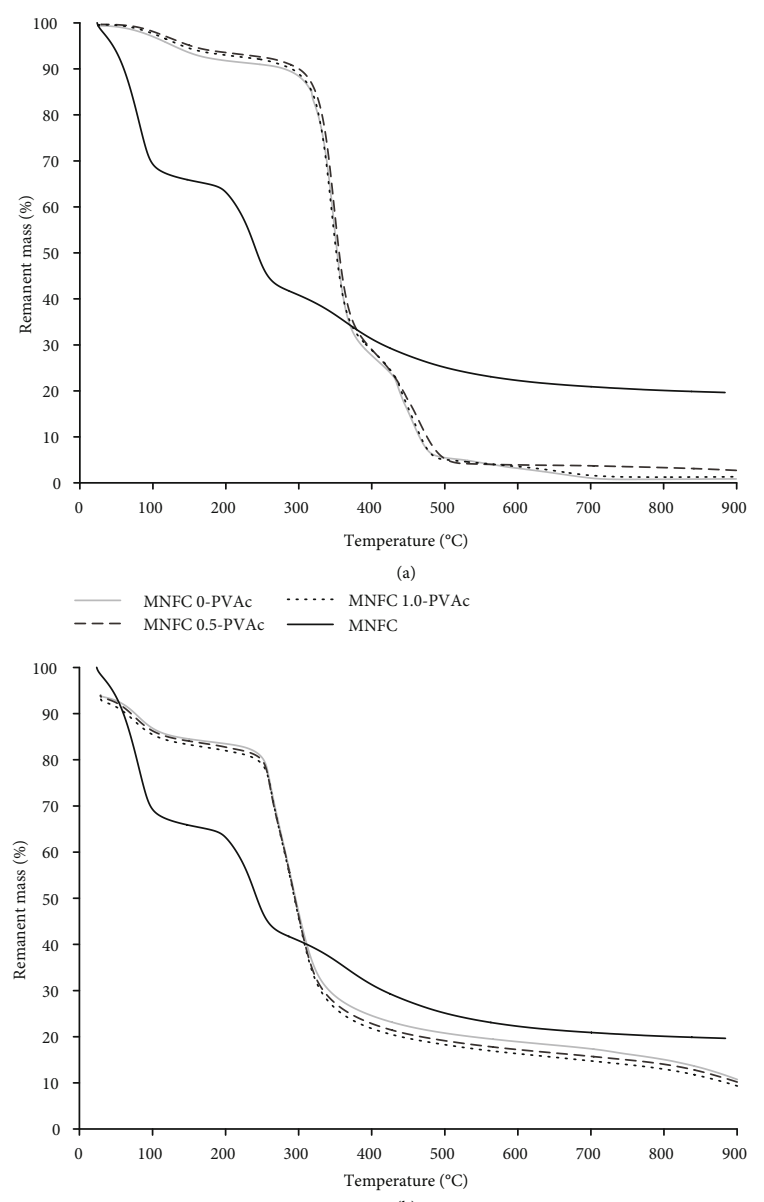

$$
\begin{array}{llll} 
& & \multicolumn{1}{c}{\text { (b) }} \\
\hdashline-- & \text { MNFC 0-UF } & \text { MNFC 0.5-UF } & \text { MNFC 1.0-UF } \\
- & & \text { MNFC }
\end{array}
$$

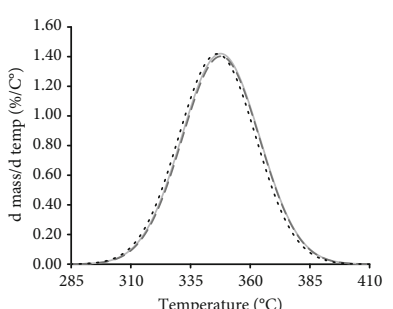

(c)

MNFC 0-PVA MNFC 0.5-PVAC

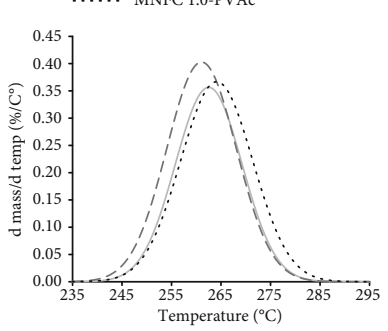
(e)

- MNFC 0-UF

--- MNFC $0.5-\mathrm{U}$

FIGURE 2: TGA and DTG of different reaction curves of PVAc (a, c, d) and UF (b, e, f) wood adhesives, adding different concentrations of MNFC. however, the methodologies of nanocellulose extraction were also different $[1,24,25]$. The decrease in MNFC thermal stability may be due to shorter MNFC chains promoted by extensive acid hydrolysis $[23,26]$.

Nanocellulose production includes cellulose degradation that involves processes of dehydration, depolymerization, decomposition of glycoside bonds, and carbonization [23]. Nanocellulose produced by acid hydrolysis incorporates surface sulfate groups to the cellulosic chains [27]. In this research, degradation of the MNFC sulfate groups can be observed at the maximum point of reaction 1 (at $210^{\circ} \mathrm{C}$ ) and in reaction 2 which started after Tmax at $241^{\circ} \mathrm{C}[23$, 26]. Roman and Winter [28] support these results when they analyzed the nanocellulose extracted by acid hydrolysis from bacterial cellulose. These authors mention that initial nanocellulose decomposition corresponds to sulfate groups added to the amorphous zones of the nanocellulose during hydrolysis, producing a first peak in the DTG curve. They also mention that sulfate groups adhere to the nanocellulose crystal chains, causing a second decomposition peak. The decomposition of sulfate group allows greater exposure of cellulose nanocrystals and its degradation, giving way to a third process of decomposition, which occurred from $300^{\circ} \mathrm{C}$ to $400^{\circ} \mathrm{C}$, with decomposition $\mathrm{Tmax}$ at $365^{\circ} \mathrm{C}$ (Figure 3).

Complete MNFC decomposition in this study took place between $338^{\circ} \mathrm{C}$ and $350^{\circ} \mathrm{C}$ (Figure 3). Studies conducted by Abraham et al. [24], Costa et al. [29], and Draman et al. [2] agreed with these results.

The analysis of the TGA curves of the MNFC 0.5-PVAc adhesive shows a slight increase in the decomposition temperature in relation to MNFC 0-PVAc (Figure 2(a)). Moreover, the thermal stability of both concentrations (Figure 2(b)) differ in UF adhesive, being higher in MNFC 1-UF. This behavior indicates increased thermal stability of the adhesive with MNFC, because degradation occurred at higher temperatures [22] due to improvement of the MNFC fibers and the polymeric matrix.

In addition, TGA curves showed 2 inflexions of the PVAc adhesives with or without MNFC (Figure 2(a)), while only one inflexion was observed with UF adhesives with or without MNFC (Figure 2(b)). The first PVAc inflexion appeared around $346^{\circ} \mathrm{C}$, and the second inflexion at $448^{\circ} \mathrm{C}$, while in UF adhesive, the inflexion occurred at $263^{\circ} \mathrm{C}$ approximately. Greater mass loss occurred between $300^{\circ} \mathrm{C}$ and $400^{\circ} \mathrm{C}$ in both adhesives in all MNFC concentrations (Figures 2(a) and 2(b)).

DTG fitting curves are shown in Figures 2(c)-2(f) for the two modified adhesives. Figures 2(c) and 2(d) show the fitted curves corresponding to the inflexions found in the TGA for PVAc, and Figures 2(e) and 2(f) the equivalent for UF. The second decomposition curve appears starting at $209^{\circ} \mathrm{C}$ with a maximum peak close to $290^{\circ} \mathrm{C}$.

For modified PVAc adhesives, reaction 1 occurred between $297^{\circ} \mathrm{C}$ and $396^{\circ} \mathrm{C}$ (Figure 2(c)), which is attributed to formation of volatile components and loss of acetate groups (deacetylation) [28]. Reaction 2 occurred between $342^{\circ} \mathrm{C}$ and $553^{\circ} \mathrm{C}$ (Figure 2(d)) and is attributed to the decomposition of the main structure of the residues of the polyene polymer that turn into carbon and hydrocarbons $[30,31]$. 


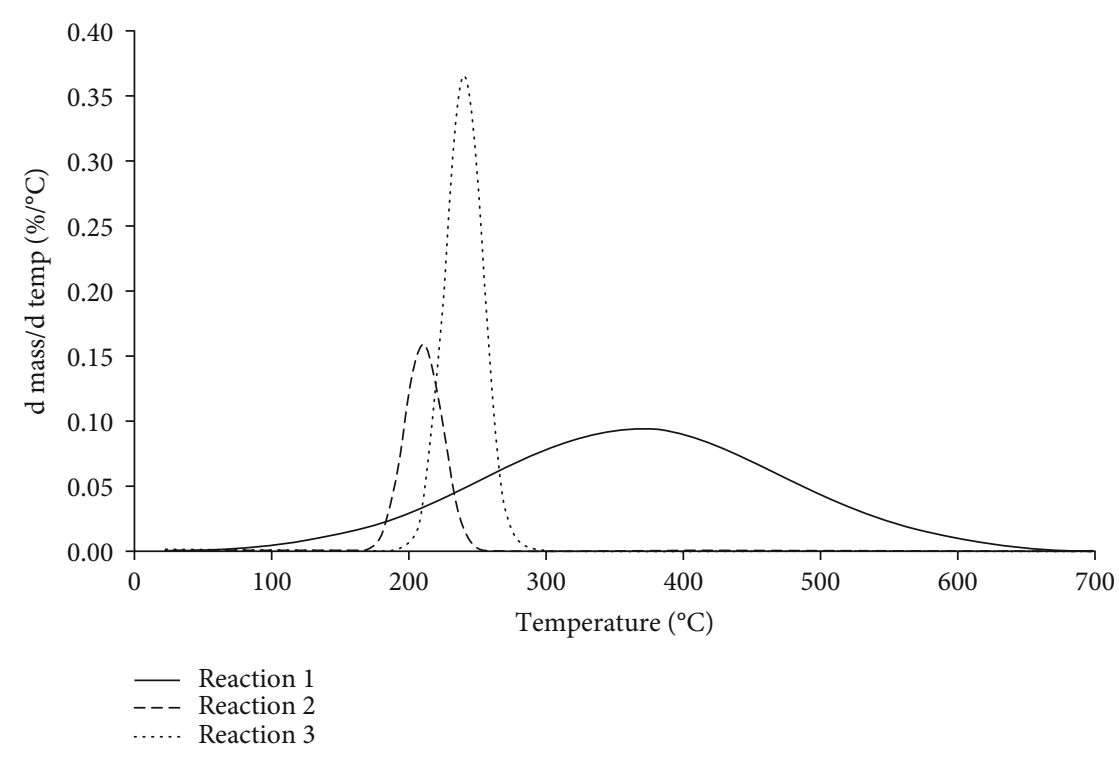

FIGURE 3: Fitting curves of three reaction ocurred during MNFC descompsition processes.

Reaction 1 in the UF adhesive (Figure 2(e)), occurred between $239^{\circ} \mathrm{C}$ and $285^{\circ} \mathrm{C}$, and it refers to the degradation of the polymer because of the partition of the polymeric chains and formaldehyde emission from the dimethylene ether groups [32]. Reaction 2 occurred within a higher range of temperatures, between $207^{\circ} \mathrm{C}$ and $380^{\circ} \mathrm{C}$ (Figure $2(\mathrm{f}$ )) and is attributable to mass loss during fragmentation of the polymer residues [33] in which methylene, methylol, dimethyl ethers, methylene glycols (formaldehyde), and components with carbonyl groups, among others, are freed [34].

Relative to MNFC effect on the temperatures of reaction, a slight increase in Tmax of the MNFC 0.5-PVAc adhesive was observed for PVAc adhesive, as in MNFC 1-UF (Figures 2(c)-2(f)) in both reactions. This is congruent with reports from Kaboorani et al. [22], who added MNFC to PVAc adhesive to determine its mechanical and thermal effects in the adhesive. Increase in reaction Tmax when adding MNFC to the adhesive was determined (Figures 2(c)-2(f)).

An important aspect to highlight considering the curves of the modified adhesives and the pristine MNFC curves is that the decomposition Tmax of the two main reactions of pure $\mathrm{MNFC}$ occurred before the reactions of the adhesives: Tmax was $347^{\circ} \mathrm{C}$ and $448^{\circ} \mathrm{C}$ on average for reactions (1) and (2), respectively, in PVAc adhesive, and in the UF adhesive, $262^{\circ} \mathrm{C}$ and $292^{\circ} \mathrm{C}$ for the reactions (1) and (2), respectively. This behavior was also observed in a study where degradation at lower temperature of MNFC extracted by acid hydrolysis from commercial microcellulose with respect to polymer (polylactide and polyvinyl acetate) occurred. This is because pure MNFC appears in chains with broader surface area and nanoscale sizes that allow its rapid decomposition [35], while adhesives present much stronger bonds between particles that make its decomposition more difficult [31].

$\mathrm{Ti}$ and $\mathrm{Tf}$ in reaction 1 of UF adhesive exhibit small variations in the three concentrations (Figures 2(e)-2(f)). Tmax increased in MNFC 1-UF, whereas in MRi, MRmax, and MRf, it tended to diminish as MNFC increased. Similar
Ti were observed in reaction 2, whereas Tmax and Tf tended to increase proportionally to MNFC percentage and were higher in MNFC 1-UF. Conversely, the remaining masses of the three decomposition points tended to decrease the higher the MNFC. Ash content was lower with 1\% MNFC in both adhesives. In both adhesives, the increase in temperatures and diminution of the remaining mass when adding the MNFC was due to disordered network or particle agglomeration containing a crystalline structure formed by the MNFC that restricts mobilization of the material and slows down its decomposition [14, 31].

Table 2 shows the decomposition kinetics parameters $A$ and $E$ for PVAc and UF wood adhesives (with different concentrations of MNFC), and pure MNFC. These parameters help to measure the reinforcement effect of MNFC on the adhesives. For PVAc, the energy reaction 1 needs for decomposition to occur increased with MNFC concentration; however, $E$ values oscillated between 211 and $213 \mathrm{~kJ} \mathrm{~mol}^{-1}$. On the other hand, in reaction 2, MNFC 0.5-PVAc exhibited the smallest value, while the MNFC 0-PVAc adhesive needed the highest amount of energy to carry out decomposition (Table 2). The evaluation of the UF adhesive showed that $E$ in reactions (1) and (2) presented the lowest values for MNFC 1-UF. MNFC 0.5-UF presented the highest $E$ value for reaction 1 (Table 2 ).

$E$ is the energy necessary for reactants to interact and cause the reaction [36]; therefore, it is also an indicator of the stability of the material [37]. MNFC 1-PVAc and MNFC 0.5 -UF adhesives presented better stability in reaction 1 because it has a higher $E$. The increase of stability in adhesives produced by the MNFC is due to the rigid network between the fibers resulting from hydrogen bonds of MNFC, increasing the resistance of the polymer to degradation [38].

$A$ is an indicator of the rate of material decomposition $[36,39]$. It exhibits similar values in reaction 1 of PVAc adhesive in the three MNFC concentrations, while in reaction 2 of such adhesive, MNFC 0.5-PVAc showed the lowest value, and MNFC 0-PVAc presented better dynamics during the 
TABLE 2: Activation energy and entropy factor for the decomposition kinetics of PVAc and UF wood adhesives (with different concentrations of MNFC), and pure MNFC.

\begin{tabular}{|c|c|c|c|c|c|}
\hline Adhesive & Reaction & MNFC (\%) & Activation energy $\left(\mathrm{kJ} \mathrm{mol}^{-1}\right)$ & Entropy factor $\left(\mathrm{s}^{-1}\right)$ & Correlation coefficient $\left(R^{2}\right)$ \\
\hline \multirow{6}{*}{ PVAc } & \multirow{3}{*}{1} & 0.0 & 211.45 & $2.87 \times 10^{17}$ & 0.95 \\
\hline & & 0.5 & 212.59 & $1.21 \times 1017$ & 0.95 \\
\hline & & 1.0 & 212.67 & $2.01 \times 1017$ & 0.95 \\
\hline & \multirow{3}{*}{2} & 0.0 & 90.10 & $1.30 \times 108$ & 0.93 \\
\hline & & 0.5 & 70.49 & $6.02 \times 104$ & 0.90 \\
\hline & & 1.0 & 83.90 & $3.52 \times 106$ & 0.93 \\
\hline \multirow{6}{*}{ UF } & \multirow{3}{*}{1} & 0.0 & 336.91 & $7.43 \times 1035$ & 0.94 \\
\hline & & 0.5 & 345.64 & $5.77 \times 1038$ & 0.94 \\
\hline & & 1.0 & 323.27 & $5.06 \times 1034$ & 0.94 \\
\hline & \multirow{3}{*}{2} & 0.0 & 118.71 & $1.10 \times 1010$ & 0.94 \\
\hline & & 0.5 & 117.03 & $8.75 \times 109$ & 0.94 \\
\hline & & 1.0 & 115.42 & $5.22 \times 109$ & 0.94 \\
\hline \multicolumn{6}{|c|}{ Reaction } \\
\hline \multirow{3}{*}{ Pure MNFC } & \multicolumn{2}{|c|}{1} & 24.36 & $4.53 \times 102$ & 0.78 \\
\hline & \multicolumn{2}{|c|}{2} & 130.42 & $4.00 \times 1012$ & 0.93 \\
\hline & \multicolumn{2}{|c|}{3} & 15.20 & $2.14 \times 101$ & 0.91 \\
\hline
\end{tabular}

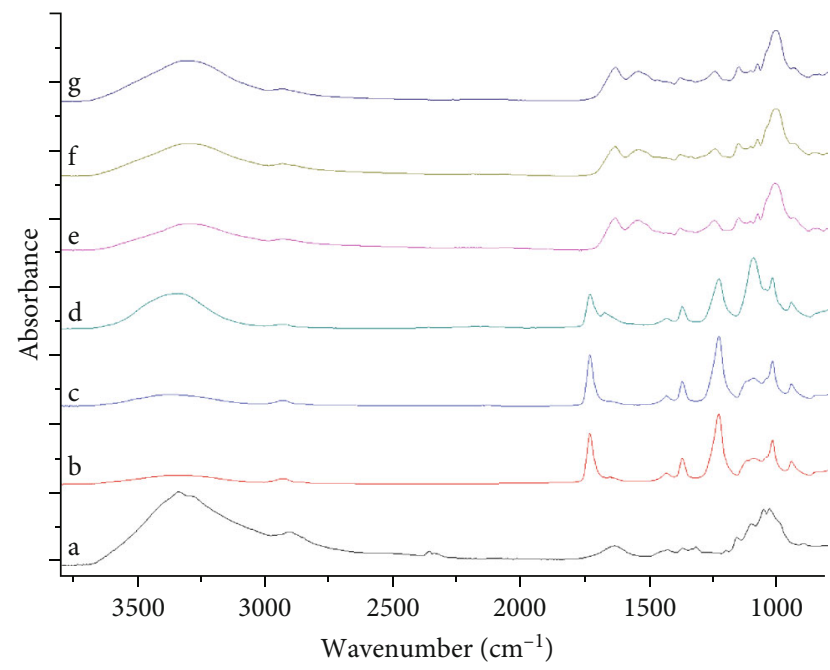

FIGURE 4: Fourier-Transform Infrared (FTIR) spectra of MNFC (a), PVAc (b), modified PVAc ((c, d) for 0.5 and $1.0 \mathrm{wt} \%$ of MNFC), UF (e), and modified UF ((f, g) for 0.5 and $1.0 \mathrm{wt} \%$ of MNFC).

reaction. For UF adhesive, in reaction 1, MNFC 1-UF exhibits the lowest $A$ value, while MNFC 0.5-UF shows the highest $A$ value, suggesting higher stability in MNFC 1-UF regarding this parameter. No differences were observed among the three concentrations in reaction 2 of adhesive UF.

3.2. Fourier-Transform Infrared (FTIR) Spectra. Figure 4 shows the FTIR spectra of the samples under study. The FTIR spectrum of MNFC showed the presence of aqueous and organic components (Figure 4(a)). The signal at
$3334 \mathrm{~cm}^{-1}$ corresponds to the stretching of $\mathrm{H}$-bonded $\mathrm{O}-\mathrm{H}$ bonds present in water molecules and polysaccharides, while at $1635 \mathrm{~cm}^{-1}$, it shows the bending mode of vibration of water molecules [37]. On the other hand, at $2914 \mathrm{~cm}^{-1}$, it shows the stretching of C-H of cellulose $[37,40]$. The lack of signals in $1500-1600 \mathrm{~cm}^{-1}$ that attributed to aromatic ring vibrations suggests the absence lignin in MNFC [41]. Other characteristic signals of cellulose occurred at $1053 \mathrm{~cm}^{-1}$ corresponding to the $\mathrm{C}-\mathrm{O}-\mathrm{C}$ of the structure of the pyranose ring [40] and $896 \mathrm{~cm}^{-1}$ with ring stretching in glucose units. According to Johar et al. [40] and Poletto et al. [42], the signals at $1053 \mathrm{~cm}^{-1}$ and $896 \mathrm{~cm}^{-1}$ indicate the presence of amorphous cellulose. The signal at $1428 \mathrm{~cm}^{-1}$ is mainly attributed to crystalline cellulose, as it is strong for crystalline cellulose and weak for amorphous cellulose [40, 42-44]. Its presence in the FTIR spectrum of MNFC (Figure 4(a)) suggests the presence of crystalline cellulose. Thus, both crystalline and amorphous celluloses are present in the MNFC extracted from pinneaple.

Pristine PVAc adhesive (Figure 4(b)) presented signals at $1725,1430,1377$, and $1245-1275 \mathrm{~cm}^{-1}$ related to the carbonyls, methyl groups, methylenes, and esters, respectively [45]. Other characteristic signals of this adhesive, usually used to identify it, are presented at signals at $1225 \mathrm{~cm}^{-1}$ and $1015 \mathrm{~cm}^{-1}[45,46]$. In addition, the peaks at 3300 and $1660 \mathrm{~cm}^{-1}$ discussed above increased for higher contents of MNFC (Figures 4(b)-4(d)).

Figures $4(\mathrm{e})-4(\mathrm{~g})$ show the spectra of the UF and modified UF. The signal at $1000 \mathrm{~cm}^{-1}$ corresponds to the $\mathrm{NH}_{3}$ group. The peak shown at $760 \mathrm{~cm}^{-1}$ corresponds to $\mathrm{N}-\mathrm{H}$ groups, and the signals 1145 and $1375 \mathrm{~cm}^{-1}$ to $\mathrm{C}-\mathrm{O}$ and C$\mathrm{N}$ bonds, respectively [33]. In addition, in $1650-1550 \mathrm{~cm}^{-1}$, characteristic resin functional groups were detected, such as 


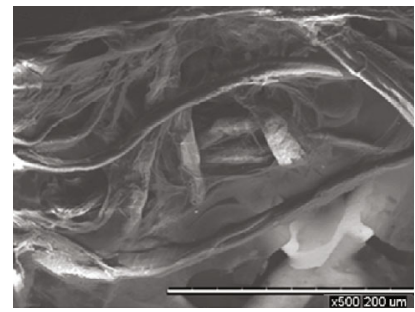

(a)

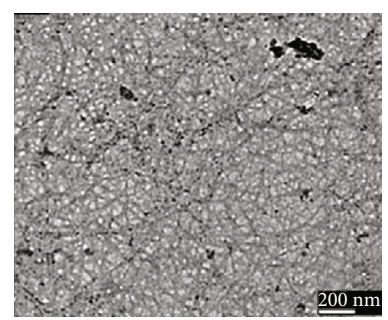

(b)

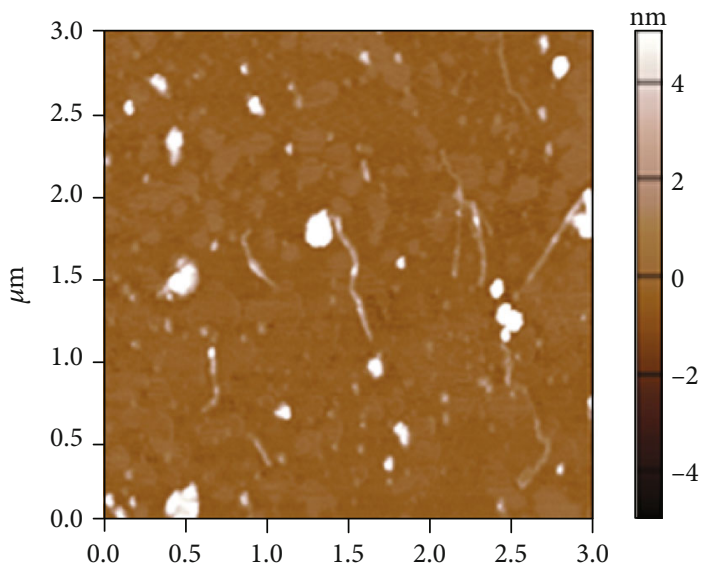

(c)

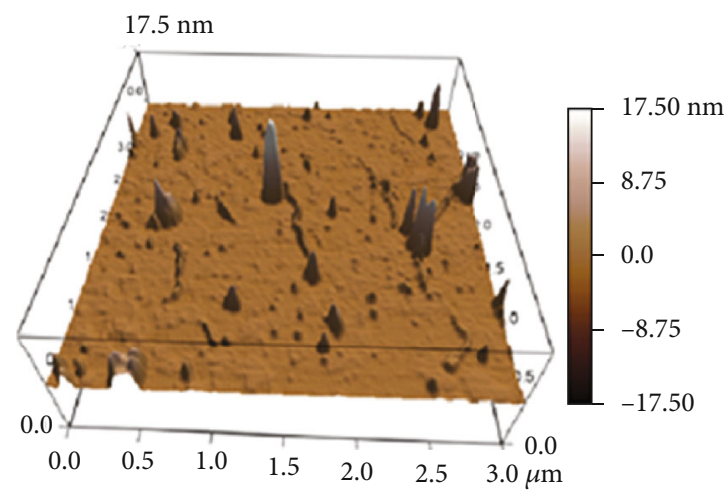

(d)

Figure 5: Results of microscopy analyses of MNFC by SEM (a), TEM (b), and AFM (c, d).

amide and $\mathrm{C}=\mathrm{O}$ [47]. Also, an increase in the concentration of MNFC resulted in an increase in the signals at $2935 \mathrm{~cm}^{-1}$ and $3300 \mathrm{~cm}^{-1}$ due to an increase in the presence of $\mathrm{C}-\mathrm{H}$ and $\mathrm{O}-\mathrm{H}$ bonds $[25,35]$.

3.3. Analysis of Microscopy Images. Microscopy images revealed existing variation in the fibers dimension and therefore the micro- and nanometric nature of the MNFC produced. SEM analysis showed fibers of micrometric sizes over $200 \mu \mathrm{m}$ in length and between 4 and $20 \mu \mathrm{m}$ in diameter (Figure 5(a)). Moreover, TEM micrographs showed a fiber network around $30 \mathrm{~nm}$ in diameter and far longer than $200 \mathrm{~nm}$ long (Figure 5(b)), which was confirmed in the AFM (Figures 5(c) and 5(d)). In general, an acid hydrolysis process generates fibers with diameters between 5 and $60 \mathrm{~nm}$ and lengths of 200-300 $\mathrm{nm}$. The process applied in this research produced fibers with aspect ratios (length/diameter) similar to those obtained by others. Abraham et al. [29] and Dos Santos et al. [1] extracted and evaluated MNFC from pineapple leaves by acid hydrolysis; the resulted dimensions were between 5 and $50 \mathrm{~nm}$ in diameter and 190 and $250 \mathrm{~nm}$ in length. Cherian et al. [48] evaluated the production of MNFC from pineapple leaves using steam explosion. They got MNFC with diameters between 5 and $60 \mathrm{~nm}$ and lengths between 200 and $300 \mathrm{~nm}$. Johar et al. [40] produced MNFC from rice using acid hydrolysis; they reported diameters between 10 and $15 \mathrm{~nm}$ and lengths between 50 and $100 \mathrm{~nm}$. Finally, Li et al. [49] used acid hydrolysis to obtain MNFC between 25 and $30 \mathrm{~nm}$ in diameter and 400 and $500 \mathrm{~nm}$ in length from branches and bark of white mulberry (Morus alba L.).
3.4. Viscosity. Figure 6 shows how the viscosity of the adhesives is affected after the incorporation of MNFC. As for MNFC in PVAc (Figure 6(a)), the viscosity diminished with increasing MNFC concentration, varying between 40 and $15 \mathrm{~Pa}$ s at the starting point. The incorporation of MNFC creates paths for humidity, allowing the presence of moisture. Adhesives with MNFC concentrations of $0.5 \%$ and $1 \%$ showed little variation because the most noticeable changes (increase) in viscosity in PVAc occurred at concentrations above $1 \%$ [14]. This is because the joints formed between MNFC particles create a stronger network. Such behavior was also observed for Chaabouni and Boufi [14], where they added MNFC to PVAc adhesive and tested it on Eucalyptus globulus. Same viscosity reduction is observed for UF adhesive, although the variation was less pronounced than for PVAc (Figure 6(b)). The change in the rheological behavior of the adhesive with the addition of MNFC comes from addition of water to the matrix, since the MNFC gel is made up of $97 \%$ water. Likewise, the shear force in the viscosity test breaks the polymer network, releasing trapped water [14] and thus decreasing the viscosity.

3.5. Bond Strength Resistance. Shear strength (SS) improved after the addition of MNFC for both PVAc and UF adhesives, in all the tropical species tested (Figure 7). The higher SS increase (35\%) occurred for $V$. ferruginea when PVAc was modified with $0.5 \%$ or $1 \%$ MNFC. No significant difference was observed in this case for the increase from $0.5 \%$ to $1 \%$ MNFC. For the other two tropical species ( $G$. arborea and C. alliodora) treated with modified PVAc, no significant differences in SS were found due to the presence of MNFC 


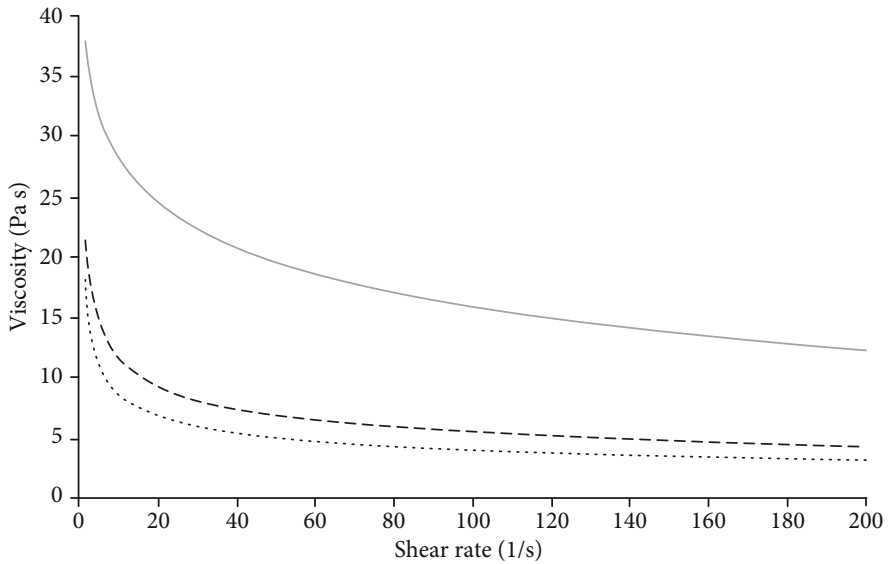

(a)

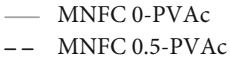

.... MNFC 1-PVAC

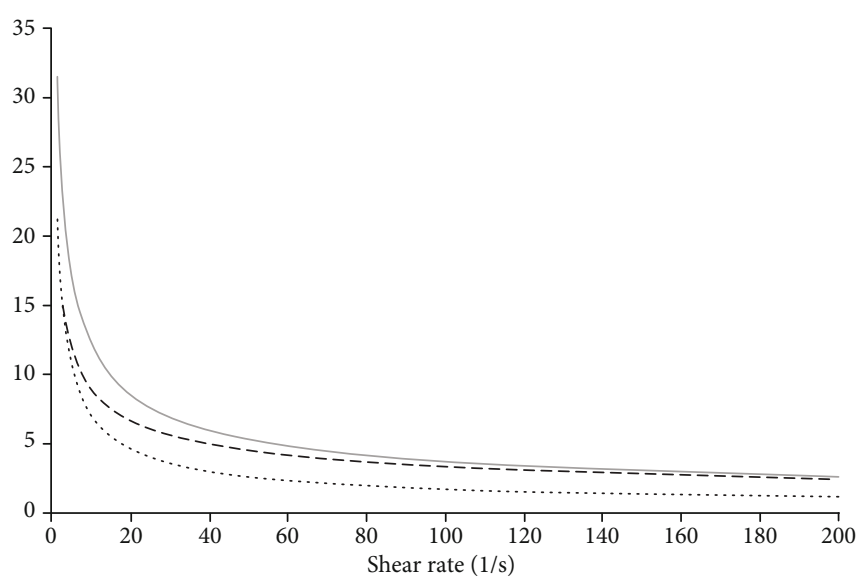

(b)

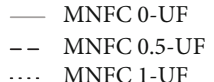

FIGURE 6: Viscosity values of PVAc and UF wood adhesives, adding different concentrations of MNFC.

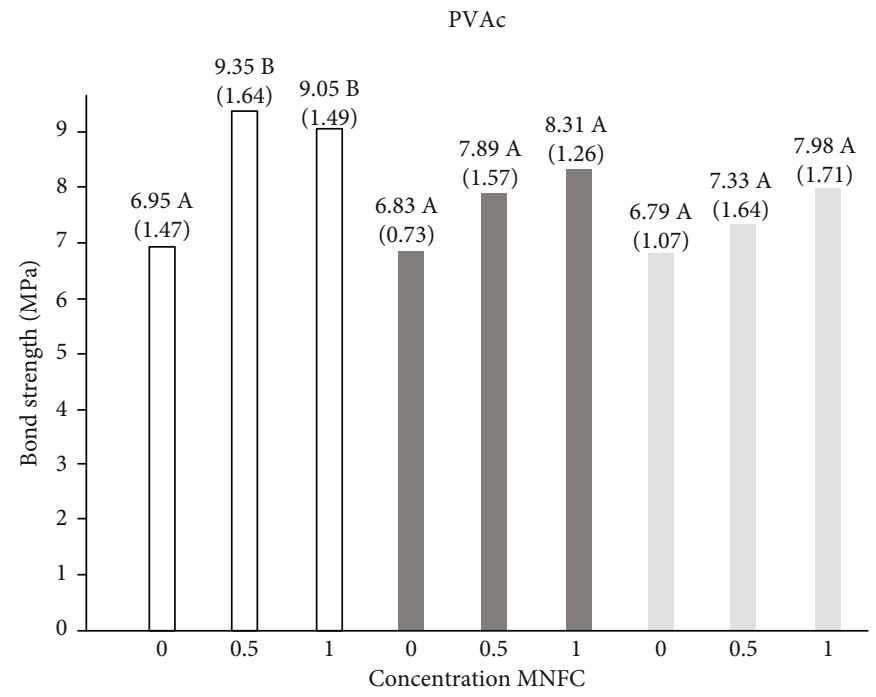

(a)

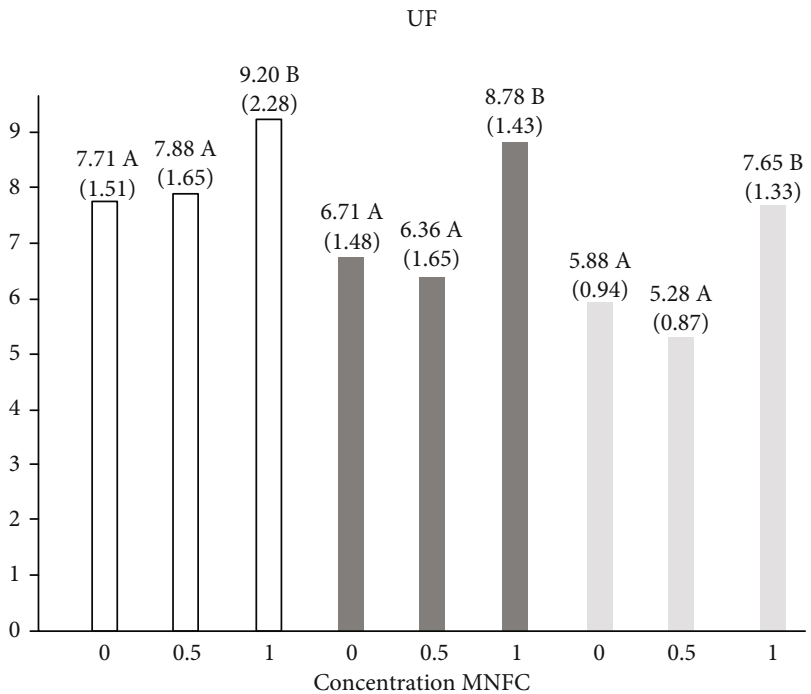

(b)

\footnotetext{
G. arborea

V. ferruginea

C. alliodora
}

FIgURE 7: Resistance of shear strength in V. ferruginea, C. alliodora, and G. arborea woods glued with PVAc (a) and UF adhesive (b) modified with MNFC in three concentrations. The values in parentheses represent standard deviation, and average values identified with different letters are statistically different at $\alpha=99 \%$.

(Figure 7(a)). For UF adhesive, only the incorporation of $1 \%$ MNFC produced significant differences with respect of control samples (Figure $7(b)$ ) for all three tropical species treated. The maximum increase for such adhesive was for C. alliodora (31\%).

The results presented above agree with previous reports, which demonstrated that small amounts of MNFC can improve interactions within a water-based adhesive [12, 50-62]. For instance, Veigel et al. [50] and Zhang et al. [51] added 5\% and $1.5 \%$ MNFC concentration to UF resins, respectively. Their results showed an important increase in the internal strength of the UF adhesive. Chaabouni and Boufi [14], Geng et al. [52], and Pracella et al. [53] added MNFC on PVAc adhesive. Their MNFC concentrations, ranging from $1 \%$ to $10 \%$, increased considerably the adhesive shear strength. Kwon et al. [15] found that the addition of 3\% MNFC in a UF adhesive increased the SS. Kwon et al. and Mantanis et al. [54] mentioned that the increase of SS was due to cellulosic fibers in the glue line filling the wood cavities together with the adhesive, allowing greater penetration, and therefore, much more strength is required to separate two pieces of wood. Likewise, the reinforcing effect of the wood- 
adhesive interface results from the formation of a network between the MNFC and polymer chains of the adhesive [55]. Almeida et al. [56] explain that MNFC's broader contact area, high resistance to traction, and rigidity allow the formation of a network of crystals that interact with the adhesive, increasing its mechanical strength.

\section{Conclusions}

Micro- and nanocellulose (MNFC) material was effectively obtained from pineapple stem by acid hydrolysis. The Thermogravimetric Analysis showed three decomposition events for the MNFC. The first two events correspond to degradation of sulfate groups, while the third is due to decomposition of the cellulosic material. After the pineapple acid hydrolysis, microscopic analyses confirm the presence of cellulosic material in the micro- and nanoscale.

The incorporation of MNFC on PVAc and UF adhesives improved their thermal stability. The viscosity of these adhesives was reduced after the addition of MNFC, mainly because of the addition of water contained in the MNFC gel. This fact was more evident in the PVAc adhesive where the initial viscosity was reduced in ca. $90 \%$ after the incorporation of 0.5 or $1 \%$ MNFC.

Significant increase of the shear strength of the glue line (SS) for both modified adhesives, PVAc and UF, was determined when $1 \%$ MNFC was incorporated. The highest increases were $35 \%$ and $31 \%$, for PVAc and UF, respectively.

In summary, the material extracted from pineapple crops in this research resulted in a combination of micro- and nanofibrillated cellulose that improved the adhesive performance of UF and PVAc. Bondability differences, through shear strength measurements, were found depending on the tropical species evaluated and the adhesive concentration used.

\section{Data Availability}

The nanocellulose data used to support the findings of this study are available from the corresponding author upon request. The following author's email can be contacted: rmoya@itcr.ac.cr.

\section{Conflicts of Interest}

The authors declare no conflict of interest.

\section{Acknowledgments}

The authors thank the Vicerrectoría de Investigación y Extensión and Unidad de Posgrado of the Instituto Tecnológico de Costa Rica for funding this study. Thanks are also given to West Virginia University, McIntire Stennis Project No. WVA00119 - 1007636. The authors thank María Teresa Vargas L. for translation and editing in English.

\section{References}

[1] R. M. dos Santos, W. P. F. Neto, H. A. Silvério, D. F. Martins, N. O. Dantas, and D. Pasquini, "Cellulose nanocrystals from pineapple leaf, a new approach for the reuse of this agro- waste," Industrial Crops and Products, vol. 50, pp. 707-714, 2013.

[2] S. F. S. Draman, R. Daik, and N. Mohd, "Eco-friendly extraction and characterization of cellulose from lignocellulosic fiber," ARPN Journal of Engineering and Applied Sciences, vol. 11, no. 16, pp. 9591-9595, 2016.

[3] C. E. Maepa, J. Jayaramudu, J. O. Okonkwo, S. S. Ray, E. R. Sadiku, and J. Ramontja, "Extraction and characterization of natural cellulose fibers from maize tassel," International Journal of Polymer Analysis and Characterization, vol. 20, no. 2, pp. 99-109, 2015.

[4] M. Darnaudery, P. Fournier, and M. Lechaudel, "Low-input pineapple crops with high quality fruit: promising impacts of locally integrated and organic fertilisation compared to chemical fertilisers," Experimental Agriculture, vol. 54, no. 2, pp. 286-302, 2016.

[5] P. Rattanapoltee and P. Kaewkannetra, "Utilization of agricultural residues of pineapple peels and sugarcane bagasse as costsaving raw materials in Scenedesmus acutus for lipid accumulation and biodiesel production," Applied Biochemistry and Biotechnology, vol. 173, no. 6, pp. 1495-1510, 2014.

[6] CANAPEP (Cámara Nacional de productores y exportadores de piña, CR), "History of pineapple production in Costa Rica," 2012, http://www.canapep.com/pina-de-costa-rica/historia.

[7] R. Moya and D. Camacho, "Production of Natural Fiber Obtained from the Leaves of Pineapple Plants (Ananas Comosus) Cultivated in Costa Rica," in Biomass and BioenergyProcessing and Properties, K. Rehman, J. Mohammad, and R. Umer, Eds., pp. 111-124, Springer, New York, USA, 2014.

[8] R. Moya, A. Berrocal, A. Rodriguez-Zuñiga et al., "Biopulp from pineapple leaf fiber produced by colonization with two white-rot fungi: Trametes versicolor and Pleurotus ostreatus," BioResources, vol. 11, no. 4, 2016.

[9] M. Mahardika, H. Abral, A. Kasim, S. Arief, and M. Asrofi, "Production of nanocellulose from pineapple leaf fibers via high-shear homogenization and ultrasonication," Fibers, vol. 6 , no. 2, p. 28, 2018.

[10] K. Wahyuningsih, E. S. Iriani, and F. Fahma, "Utilization of cellulose from pineapple leaf fibers as nanofiller in polyvinyl alcohol-based film," Indonesian Journal of Chemistry, vol. 16, no. 2, p. 181, 2016.

[11] D. Bourreau, Y. Aimene, J. Beauchêne, and B. Thibaut, "Feasibility of glued laminated timber beams with tropical hardwoods," European Journal of Wood and Wood Products, vol. 71, no. 5, pp. 653-662, 2013.

[12] E. Mahrdt, S. Pinkl, C. Schmidberger, H. W. G. Herwijnenvan, S. Veigel, and W. Gindl-Altmutter, "Effect of addition of microfibrillated cellulose to urea-formaldehyde on selected adhesive characteristics and distribution in particle board," Cellulose, vol. 23, no. 1, pp. 571-580, 2016.

[13] N. Ayrilmis, J. H. Kwon, S. H. Lee, T. H. Han, and C. W. Park, "Microfibrillated-cellulose-modified urea-formaldehyde adhesives with different F/U molar ratios for wood-based composites," Journal of Adhesion Science and Technology, vol. 30, no. 18, pp. 2032-2043, 2016.

[14] O. Chaabouni and S. Boufi, "Cellulose nanofibrils/polyvinyl acetate nanocomposite adhesives with improved mechanical properties," Carbohydrate Polymers, vol. 156, pp. 64-70, 2017.

[15] J. H. Kwon, S.-H. Lee, N. Ayrilmis, and T. H. Han, “Tensile shear strength of wood bonded with urea-formaldehyde with 
different amounts of microfibrillated cellulose," International Journal of Adhesion and Adhesives, vol. 60, pp. 88-91, 2015.

[16] R. Moya, C. Tenorio, C. Salas, and F. Muñoz, Tecnología de la madera de plantaciones forestales, Editorial Tecnológica de Costa Rica, Cartago, Costa Rica, 2017.

[17] A. A. Oun and J. W. Rhim, "Characterization of nanocelluloses isolated from Ushar (Calotropis procera) seed fiber: effect of isolation method," Materials Letters, vol. 168, pp. 146-150, 2016.

[18] D. Gaspar, S. N. Fernandes, A. G. Oliveirade et al., "Nanocrystalline cellulose applied simultaneously as the gate dielectric and the substrate in flexible field effect transistors," Nanotechnology, vol. 25, no. 9, article 094008, 2014.

[19] A. Saddawi, J. M. Jones, A. Williams, and M. A. Wojtowicz, "Kinetics of the thermal decomposition of biomass," Energy \& Fuels, vol. 24, no. 2, pp. 1274-1282, 2010.

[20] J. Kotz, P. M. Treichel, and J. R. Townsend, Chemistry \& Chemical Reactivity, Thomson Books/Cole, Canadá, 2009.

[21] ASTM D905-08, "Standard test method for strength properties of adhesive bonds in shear by compression loading," in Annual Book of ASTM Standards, ASTM International, USA, 2013.

[22] A. Kaboorani, B. Riedl, P. Blanchet, M. Fellin, O. Hosseinaei, and S. Wang, "Nanocrystalline cellulose (NCC): a renewable nano-material for polyvinyl acetate (PVA) adhesive," European Polymer Journal, vol. 48, no. 11, pp. 1829-1837, 2012.

[23] A. Kumar, Y. S. Negi, V. Choudhary, and N. K. Bhardwaj, "Characterization of cellulose nanocrystals produced by acidhydrolysis from sugarcane bagasse as agro-waste," Journal of Materials Physics and Chemistry, vol. 2, no. 1, pp. 1-8, 2014.

[24] L. M. M. Costa, G. M. de Olyveira, B. M. Cherian, A. L. Leão, S. F. de Souza, and M. Ferreira, "Bionanocomposites from electrospun PVA/pineapple nanofibers/Stryphnodendron adstringens bark extract for medical applications," Industrial Crops and Products, vol. 41, pp. 198-202, 2013.

[25] D. Hammiche, A. Boukerrou, H. Djidjelli, Y. Grohens, A. Bendahou, and B. Seantier, "Characterization of cellulose nanowhiskers extracted from alfa fiber and the effect of their dispersion methods on nanocomposite properties," Journal of Adhesion Science and Technology, vol. 30, no. 17, pp. 1899-1912, 2016.

[26] H. Kargarzadeh, I. Ahmad, I. Abdullah, A. Dufresne, S. Y. Zainudin, and R. M. Sheltami, "Effects of hydrolysis conditions on the morphology, crystallinity, and thermal stability of cellulose nanocrystals extracted from kenaf bast fibers," Cellulose, vol. 19, no. 3, pp. 855-866, 2012.

[27] W. Chen, H. Yu, Y. Liu, P. Chen, M. Zhang, and Y. Hai, "Individualization of cellulose nanofibers from wood using high-intensity ultrasonication combined with chemical pretreatments," Carbohydrate Polymers, vol. 83, no. 4, pp. 18041811, 2011.

[28] M. Roman and W. T. Winter, "Effect of sulfate groups from sulfuric acid hydrolysis on the thermal degradation behavior of bacterial cellulose," Biomacromolecules, vol. 5, no. 5, pp. 1671-1677, 2004.

[29] E. Abraham, B. Deepa, L. A. Pothan et al., "Extraction of nanocellulose fibrils from lignocellulosic fibres: a novel approach," Carbohydrate Polymers, vol. 86, no. 4, pp. 1468-1475, 2011.

[30] B. J. Holland and J. N. Hay, "The thermal degradation of poly(vinyl acetate) measured by thermal analysis-Fourier transform infrared spectroscopy," Polymer, vol. 43, no. 8, pp. 2207-2211, 2002.
[31] K. Y. Lee, Y. Aitomäki, L. A. Berglund, K. Oksman, and A. Bismarck, "On the use of nanocellulose as reinforcement in polymer matrix composites," Composites Science and Technology, vol. 105, pp. 15-27, 2014.

[32] E. Roumeli, E. Papadopoulou, E. Pavlidou et al., "Synthesis, characterization and thermal analysis of urea-formaldehyde/nanoSiO 2 resins," Thermochimica Acta, vol. 527, pp. 33-39, 2012.

[33] X. Jiang, C. Li, Y. Chi, and J. Yan, "TG-FTIR study on ureaformaldehyde resin residue during pyrolysis and combustion," Journal of Hazardous Materials, vol. 173, no. 1-3, pp. 205-210, 2010.

[34] R. Moya, A. Rodríguez-Zúñiga, and J. Vega-Baudrit, "Effects of adding multiwall carbon nanotubes on performance of polyvinyl acetate and urea-formaldehyde adhesives in tropical timber species," Journal of Nanomaterials, vol. 2015, no. 1, Article ID 895650, 15 pages, 2015.

[35] W. Li, R. Wang, and S. Liu, "Nanocrystalline cellulose prepared from softwood Kraft pulp via ultrasonic-assisted acid hydrolysis," BioResources, vol. 6, no. 4, pp. 4271-4281, 2011.

[36] K. J. Laidler, "The development of the Arrhenius equation," Journal of Chemical Education, vol. 61, no. 6, pp. 494-498, 1984.

[37] F. K. Liew, S. Hamdan, M. R. Rahman et al., "Synthesis and characterization of cellulose from green bamboo by chemical treatment with mechanical process," Journal of Chemistry, vol. 2015, Article ID 212158, 6 pages, 2015.

[38] S. Boufi, H. Kaddami, and A. Dufresne, "Mechanical performance and transparency of nanocellulose reinforced polymer nanocomposites," Macromolecular Materials and Engineering, vol. 299, no. 5, pp. 560-568, 2014.

[39] A. A. Rowe, M. Tajvidi, and D. J. Gardner, "Thermal stability of cellulose nanomaterials and their composites with polyvinyl alcohol (PVA)," Journal of Thermal Analysis and Calorimetry, vol. 126, no. 3, pp. 1371-1386, 2016.

[40] N. Johar, I. Ahmad, and A. Dufresne, "Extraction, preparation and characterization of cellulose fibres and nanocrystals from rice husk," Industrial Crops and Products, vol. 37, no. 1, pp. 93-99, 2012.

[41] J. I. Morán, V. A. Álvarez, V. P. Cyras, and A. Vázquez, "Extraction of cellulose and preparation of nanocellulose from sisal fibers," Cellulose, vol. 15, no. 1, pp. 149-159, 2008.

[42] M. Poletto, H. Ornaghi, and A. Zattera, "Native cellulose: structure, characterization and thermal properties," Materials, vol. 7, no. 9, pp. 6105-6119, 2014.

[43] J. Lu, P. Askeland, and L. T. Drzal, "Surface modification of microfibrillated cellulose for epoxy composite applications," Polymer, vol. 49, no. 5, pp. 1285-1296, 2008.

[44] H. Sanaeishoar, M. Sabbaghan, and D. S. Argyropoulos, "Ultrasound assisted polyacrylamide grafting on nanofibrillated cellulose," Carbohydrate Polymers, vol. 181, pp. 1071-1077, 2018.

[45] Y. Mansoori, A. Akhtarparast, M. Reza Zamanloo, G. Imanzadeh, and T. M. Masooleh, "Polymer-montmorillonite nanocomposites: chemical grafting of polyvinyl acetate onto Cloisite 20A," Polymer Composites, vol. 32, no. 8, pp. 1225-1234, 2011.

[46] M. K. Pal and J. Gautam, "Effects of inorganic nanofillers on the thermal degradation and UV-absorbance properties of polyvinyl acetate," Journal of Thermal Analysis and Calorimetry, vol. 111, no. 1, pp. 689-701, 2013. 
[47] S. Samaržija-Jovanović, V. Jovanović, S. Konstantinović, G. Marković, and M. Marinović-Cincović, "Thermal behavior of modified Urea-formaldehyde resins," Journal of Thermal Analysis and Calorimetry, vol. 104, no. 3, pp. 1159-1166, 2011.

[48] B. M. Cherian, A. L. Leão, S. F. de Souza, S. Thomas, L. A. Pothan, and M. Kottaisamy, "Isolation of nanocellulose from pineapple leaf fibres by steam explosion," Carbohydrate Polymers, vol. 81, no. 3, pp. 720-725, 2010.

[49] R. Li, J. Fei, Y. Cai, Y. Li, J. Feng, and J. Yao, "Cellulose whiskers extracted from mulberry: a novel biomass production," Carbohydrate Polymers, vol. 76, no. 1, pp. 94-99, 2009.

[50] S. Veigel, U. Müller, J. Keckes, M. Obersriebnig, and W. GindlAltmutter, "Cellulose nanofibrils as filler for adhesives: effect on specific fracture energy of solid wood-adhesive bonds," Cellulose, vol. 18, no. 5, pp. 1227-1237, 2011.

[51] H. Zhang, J. Zhang, S. Song, G. Wu, and J. Pu, "Modified nanocrystalline cellulose from two kinds of modifiers used for improving formaldehyde emission and bonding strength of urea-formaldehyde resin adhesive," BioResources, vol. 6, no. 4, pp. 4430-4438, 2011.

[52] S. Geng, M. M. U. Haque, and K. Oksman, "Crosslinked poly(vinyl acetate) (PVAc) reinforced with cellulose nanocrystals (CNC): Structure and mechanical properties," Composites Science and Technology, vol. 126, pp. 35-42, 2016.

[53] M. Pracella, M. M. Haque, and D. P. V. Alvarez, "Preparation and characterization of PLA nanocomposites with nanocellulose filled PVAC," in ECCM15 - 15th The European conference on composite materials, Venice, Italy, 2012.

[54] G. I. Mantanis, E. T. Athanassiadou, M. C. Barbu, and K. Wijnendaele, "Adhesive systems used in the European particleboard, MDF and OSB industries," Wood Material Science \& Engineering, vol. 13, no. 2, pp. 104-116, 2018.

[55] N. Grishkewich, N. Mohammed, J. Tang, and K. C. Tam, "Recent advances in the application of cellulose nanocrystals," Current Opinion in Colloid \& Interface Science, vol. 29, pp. 3245, 2017.

[56] R. G. de Almeida Mesquita, L. M. Mendes, A. R. Sanadi et al., "Urea formaldehyde and cellulose nanocrystals adhesive: studies applied to sugarcane bagasse particleboards," Journal of Polymers and the Environment, vol. 26, no. 7, pp. 3040-3050, 2018.

[57] E. Atta-Obeng, B. Via, O. Fasina, M. Auad, and W. Jiang, "Cellulose reinforcement of phenol formaldehyde: characterization and chemometric elucidation," International Journal of Composite Materials, vol. 3, no. 3, pp. 61-68, 2013.

[58] B. D. Park, N. Ayrilmis, J. H. Kwon, and T. H. Han, "Effect of microfibrillated cellulose addition on thermal properties of three grades of urea-formaldehyde resin," International Journal of Adhesion and Adhesives, vol. 72, pp. 75-79, 2017.

[59] S. Veigel, J. Rathke, M. Weigl, and W. Gindl-Altmutter, "Particle Board and Oriented Strand Board Prepared with Nanocellulose- Reinforced Adhesive," Journal of Nanomaterials, vol. 2012, Article ID 158503, 8 pages, 2012.

[60] M. I. Aranguren, N. E. Marcovich, W. Salgueiro, and A. Somoza, "Effect of the nano-cellulose content on the properties of reinforced polyurethanes. A study using mechanical tests and positron anihilation spectroscopy," Polymer Testing, vol. 32, no. 1, pp. 115-122, 2013.
[61] H. M. Ng, L. T. Sin, T. T. Tee et al., "Extraction of cellulose nanocrystals from plant sources for application as reinforcing agent in polymers," Composites Part B: Engineering, vol. 75, pp. 176-200, 2015.

[62] P. Aramwit and N. Bang, "The characteristics of bacterial nanocellulose gel releasing silk sericin for facial treatment," BMC Biotechnology, vol. 14, no. 1, p. 104, 2014. 